\author{
Пономаренко А.Г., \\ Саркисян Н.С., \\ Куличенко А.Н.
}

\begin{abstract}
Федеральное казенное учреждение зАравоохранения "Ставропольский научно-исследовательский противочумный институт" Федеральной службы по надзору в сфере защиты прав потребителей и благополучия человека, 355035, г. Ставрополь, Российская Федерация
\end{abstract}

В обзоре приведен анализ иммунопатологической концепции патогенеза бруцеллеза, основанной на данных о молекулярно-клеточных механизмах взаимодействия бруцелл с факторами иммунитета макроорганизма. Дана характеристика основных факторов патогенности бруцелл, обеспечивающих реализацию стратегии скрытого проникновения, ингибирования факторов естественной резистентности и уклонения от адаптивного иммунитета.

Финансирование. Исследование не имело финансовой поддержки.

Конфликт интересов. Авторы заявляют об отсутствии конфликта интересов.

Вклад авторов. Сбор, обработка материала, написание текста - Пономаренко Д.Г., Саркисян Н.С.; редактирование, утверждение окончательного варианта статьи - Куличенко А.Н.

Для цитирования: Пономаренко Д.Г., Саркисян Н.С., Куличенко А.Н. Патогенез бруцеллеза: анализ иммунопатологической концепции (материал для подготовки лекции) // Инфекционные болезни: новости, мнения, обучение. 2020 . Т. 9, № 3. C. 96-105. D0I: https://doi.org/10.33029/2305-3496-2020-9-3-96-105

Статья поступила в редакцию 31.03.2020. Принята в печать 02.07.2020.

\title{
Pathogenesis of brucellosis: analysis of the immunopathological concept
}

Ponomarenko D.G., Sarkisyan N.S., Kulichenko A.N.
Stavropol Research Anti-Plague Institute, 355035, Stavropol, Russian Federation

The review analyzes the immunopathological concept of brucellosis pathogenesis based on the regularities of molecular-cellular mechanisms of brucellosis interaction with macroorganism immunity factors. Herein is given the characteristic of the main pathogenicity factors of Brucella that ensure the implementation of the strategy of "hidden" penetration, inhibition of natural resistance factors and evasion of adaptive immunity.

Funding. There was no financial support for writing this publication.

Conflict of interests. The authors declare no conflict of interest.

Contributions. Collecting, processing the material, writing the text - Ponomarenko D.G., Sarkisyan N.S.; editing, approval of the final version of the article - Kulichenko A.N.

For citation: Ponomarenko D.G., Sarkisyan N.S., Kulichenko A.N. Pathogenesis of brucellosis: analysis of the immunopathological concept. Infektsionnye bolezni: novosti, mneniya, obuchenie [Infectious Diseases: News, Opinions, Training]. 2020; 9 (3): 96-105. DOI: https://doi.org/10.33029/2305-3496-2020-9-3-96-105 (in Russian)

Received 31.03.2020. Accepted 02.07.2020.

Ключевые слова:

бруцеллез,

патогенез,

персистенция,

факторь

патогенности

бруцелл,

иммунный ответ,

инфекционный

иммунитет
Keywords: brucellosis, pathogenesis, persistence, brucellosis pathogenicity factors, immune response, infectious immunity 
b руцеллез на современном этапе рассматривается специалистами как один из наиболее опасных зоонозов. Инфицирование человека возбудителями бруцеллеза обычно происходит в результате прямого контакта с выделениями, кровью или сырьем от больных бруцеллезом животных, употребления контаминированных бруцеллами необеззараженных продуктов животного происхождения (молоко, кисломолочные и мясные продукты), вдыхания воздушнопылевой смеси, содержащей контаминированные бруцеллами фрагменты шерсти, навоза, земли и др. [1].

Практически любой орган и система могут поражаться при бруцеллезе. Это является следствием генерализованного процесса, характерного для заболеваний с выраженными иммунопатологическими реакциями, протекающими на фоне системного воспаления и эндотоксикоза [2].

\section{Основные факторы патогенности бручемм. Стадии развития бручеммезной инфекции (патогенетические аспекты)}

Известно, что, в отличие от многих патогенов, бруцеллы не проявляют «прямой» агрессии в отношении клеток хозяина - не синтезируют экзотоксины, экзопротеазы, цитолизины или другие агрессивные для макроорганизма субстанции. Воспалительные реакции при бруцеллезе слабоманифестные, имеют преимущественно пролиферативный характер и теснейшим образом ассоциированы с реакциями иммунитета. Вместе с тем воспаление достаточно продолжительное, что обусловлено длительной персистенцией бруцелл в инфицированных тканях, и это в конечном итоге приводит к воспалительной альтерации [2].

Взаимодействие in vivo патогена с клетками иммунной системы происходит в несколько этапов, каждый из которых обусловлен проявлением факторов патогенности бруцелл. В процессе эволюции бруцеллы приобрели более 250 белковых детерминант патогенности, которые определяют в том числе молекулярную мимикрию, что способствует выживанию и размножению возбудителя в организме хозяина $[3,4]$.

Многие аспекты взаимодействия «паразит-хозяин» указывают на определяющую роль нарушений функции иммунитета в патогенезе инфекционной болезни. Основные факторы патогенности бруцелл обеспечивают реализацию стратегии «скрытого» проникновения в макроорганизм, ингибирование факторов естественной резистентности и уклонение от адаптивного иммунитета (см. таблицу) [2, 5-10].

В динамике бруцеллезной инфекции условно можно выделить 5 основных фаз: лимфогенного заноса (инициальная фаза), гематогенного заноса (первичная генерализация), полиочаговых локализаций, экзоочаговых обсеменений (вторичная генерализация) и резидуального метаморфоза [11-13].

В инициальную фазу бруцеллы проникают в организм хозяина через поврежденную кожу или слизистые оболочки (в том числе неповрежденные), захватываются фагоцитами и током лимфы (лимфогенно) заносятся в регионарные лимфоузлы. В лимфоузлах накапливаются с образованием пер- вичного бруцеллезного комплекса. Эта фаза хронологически соответствует инкубационному периоду болезни - происходит иммунологическая перестройка организма с образованием специфических антител.

При массивном накоплении возбудителя в условиях формирования индуцированного бруцеллами незавершенного фагоцитоза лимфатические узлы становятся «резервуаром» (очагом) бактерий, откуда патоген может поступать в кровь и распространяться по всему организму, инициируя формирование II фазы - гематогенного заноса (первичная генерализация).

Во II фазу развиваются бактериемия и эндотоксинемия, появляется клиническая симптоматика острого бруцеллеза. С током крови бактерии разносятся по органам, богатым ретикулоэндотелием, и фиксируются в них (фаза полиочаговых локализаций). Далее происходит активация клеток мононуклеарно-макрофагальной системы (МMC), в тканях развиваются диффузные, иммуновоспалительные изменения, формируются очаговые скопления макрофагов с внутриклеточно-паразитирующими в них бруцеллами. Это защитно-приспособительные процессы, направленные на снижение интенсивности бактериемии, локализацию бактерий.

Незавершенный фагоцитоз бруцелл провоцирует явление эндоцитобиоза и активное размножение патогена в цитоплазме фагоцитов. Большинство фагоцитов гибнет, и бактерии, высвобождаясь, гемато- и лимфогенно разносятся по организму (селезенка, печень, костный мозг, лимфатические узлы и др.).

C началом генерализации патологического процесса и формирования метастатических вторичных полиорганных очагов инфекции в виде специфических гранулем происходит иммуноаллергическая перестройка организма (гиперчувствительность замедленного типа).

Фаза резидуального метаморфоза соответствует исходам бруцеллеза, завершающегося либо полной резорбцией (рассасывание, деградация) воспалительных образований, либо формированием стойких функционально-органических изменений в пораженных тканях [11-15].

\section{Взаимодействие патогена с факторами иммунной системы макроорганизма. Роль основных факторов патогенности в инАушировании АИсфункшии иммунной системы хозяина}

Биологический цикл бруцелл в организме хозяина в условиях воздействия на микроорганизм факторов индуцированного патогеном иммунного ответа (в естественных для патогена условиях) характеризуется длительностью течения. На начальных этапах после инфицирования бруцеллы используют механизмы, направленные на противодействие активации факторов врожденного иммунитета за счет присутствия у бактерий особых (модифицированных) патоген-ассоциированных молекулярных структур (PAMPs).

Эффекторные субстанции Brucella BtpA/Btp1/ТсрB обеспечивают блокировку (экранирование) распознавания PAMPs Toll-подобными рецепторами (TLR) фагоцитов, пода- 
Основные факторы патогенности бруцемл

\begin{tabular}{|c|c|c|}
\hline Фактор патогенности & Функция & Биологический эффект \\
\hline $\begin{array}{l}\text { Система секреции IV типа } \\
\text { (T4SS) }\end{array}$ & $\begin{array}{l}\text { Главный фактор патогенности. Обеспечивает } \\
\text { направленный внутриклеточный трафик } \\
\text { к репликативной нише }\end{array}$ & $\begin{array}{l}\text { Выживание и персистенция бруцем^ внутри } \\
\text { фагоцитов }\end{array}$ \\
\hline $\begin{array}{l}\text { Сенсорно-регуляторная система } \\
\text { аАаптации (BvrS/BvrR) }\end{array}$ & $\begin{array}{l}\text { Контроль метаболизма бруцемл при внутри- } \\
\text { клеточной ^окализации }\end{array}$ & $\begin{array}{l}\text { ААаптация и персистенция бруцемл внутри } \\
\text { фагоцитов }\end{array}$ \\
\hline 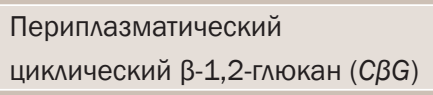 & $\begin{array}{l}\text { Образование Brucella-содержащих вакуолей } \\
\text { (BCV) }\end{array}$ & Персистенция бруцем^ внутри фагоцитов \\
\hline $\begin{array}{l}\text { Периплазматические белки } \\
\text { ЕірА, ЕірВ }\end{array}$ & $\begin{array}{l}\text { Обеспечение целостности клеточной оболочки } \\
\text { бруцем^ и регуляция клеточного Аеления }\end{array}$ & $\begin{array}{l}\text { Выживание и размножение бруцем^ внутри } \\
\text { фагоцитов }\end{array}$ \\
\hline $\begin{array}{l}\text { Белок А пролинарацемазы } \\
\text { (PrpA) }\end{array}$ & $\begin{array}{l}\text { Иммуномодулятор. } \\
\text { Поликлональный В-клеточный митоген. } \\
\text { Индуктор секреции интерлейкина-10 } \\
\text { (И^-10) - противовоспалительного цитокина }\end{array}$ & $\begin{array}{l}\text { Цитокин-индуцированная Т-клеточная } \\
\text { анергия. Подавление естественного и } \\
\text { приобретенного иммунного ответа хозяина }\end{array}$ \\
\hline BtpA/Btp1/ТсрB & $\begin{array}{l}\text { Блокировка (экранирование) паттерн- } \\
\text { распознающих рецепторов (РАMP) - } \\
\text { TLR2-, TLR4-фагоцитов и ингибирование } \\
\text { интенсивности иммуновоспалительных } \\
\text { реакций. } \\
\text { Ингибирование цитотоксичности лимфоцитов } \\
\text { (CTL) }\end{array}$ & $\begin{array}{l}\text { Незаметное проникновение в организм } \\
\text { хозяина (stealthy-стратегия). } \\
\text { Уклонение от адаптивного иммунитета }\end{array}$ \\
\hline $\begin{array}{l}\text { Модифицированный флагемлин } \\
\text { (FliC) }\end{array}$ & Слабый инауктор TLR5 фагоцитов & $\begin{array}{l}\text { Незаметное проникновение в организм } \\
\text { хозяина (stealthy-стратегия) }\end{array}$ \\
\hline ^ипополисахариА (LPS) & $\begin{array}{l}\text { Слабый индуктор провоспалительных } \\
\text { цитокинов. } \\
\text { Ингибирование слияния фагосомы } \\
\text { с лизосомами. } \\
\text { Защита от системы комплемента. } \\
\text { Индуктор секреции И^-10. } \\
\text { Ингибирование антигенпрезентации } \\
\text { (МHC II). } \\
\text { Интерференция рецепторного комплекса } \\
\text { TLR4-MD-2 (подавление созревания } \\
\text { AенАритных клеток). } \\
\text { Пироген (слабый пироген). } \\
\text { А^мерген }\end{array}$ & $\begin{array}{l}\text { Слабый иммунный ответ на LPS. } \\
\text { Незавершенный фагоцитоз. } \\
\text { Устойчивость к бактерицинным свойствам } \\
\text { крови. } \\
\text { Т-клеточная анергия. } \\
\text { Снижение эффективности естественного } \\
\text { и адаптивного иммунитета. } \\
\text { Ингибирование естественного иммунитета, } \\
\text { уклонение от адаптивного иммунитета. } \\
\text { Гектическая лихорадка неправильного типа. } \\
\text { Формирование специфической } \\
\text { сенсибилизации }\end{array}$ \\
\hline $\begin{array}{l}\text { Cu-Zn-SOD } \\
\text { (супероксиАдисмутаза) }\end{array}$ & $\begin{array}{l}\text { ААаптация бруцемл к окислительному стрессу } \\
\text { при энАоцитобиозе }\end{array}$ & \multirow[t]{2}{*}{$\begin{array}{l}\text { ААаптация и персистенция бруцемл внутри } \\
\text { фагоцитов }\end{array}$} \\
\hline Каталаза (САT) & $\begin{array}{l}\text { ААаптация бруцем^ к окислительному стрессу } \\
\text { при энАоцитобиозе }\end{array}$ & \\
\hline Уреаза (ure) & Защита в кислой среде & \multirow{3}{*}{$\begin{array}{l}\text { Выживание бактерий при их локализации } \\
\text { в желудке (желудочном соке) }\end{array}$} \\
\hline $\begin{array}{l}\text { А^ки^ гипероксиА реАуктаза } \\
\text { (ahpC\&D) }\end{array}$ & $\begin{array}{l}\text { Аетоксикация } \mathrm{H}_{2} \mathrm{O}_{2} \text { и гиАропероксидов, } \\
\text { возникающих как результат аэробного } \\
\text { обмена у бруцем^ }\end{array}$ & \\
\hline ЦитохромоксиАаза (суdDCAB) & $\begin{array}{l}\text { Защита от возАействия активных форм } \\
\text { кислорода при проникновении в фагоцит }\end{array}$ & \\
\hline Оксилредуктаза азота (norD) & ААаптация к агрессивной среде внутри клетки & $\begin{array}{l}\text { Размножение в условиях низкого содержания } \\
\text { кислорода }\end{array}$ \\
\hline ААенин- и гуанинмонофосфаты & Угнетение функции фагоцитов & Подавление естественного иммунитета \\
\hline Omp 19 & $\begin{array}{l}\text { Ингибирование презентации антигена CD4+ } \\
\text { Т-лимфоцитам. } \\
\text { Индукция апоптоза Т-клеток }\end{array}$ & $\begin{array}{l}\text { Подавление формирования аАаптивного } \\
\text { иммунитета. } \\
\text { Уклонение от аАаптивного иммунитета }\end{array}$ \\
\hline Omp 25 & $\begin{array}{l}\text { Подавление синтеза фактора некроза } \\
\text { опухоли } \alpha \text { макрофагами и дендритными } \\
\text { клетками }\end{array}$ & $\begin{array}{l}\text { Снижение интенсивности } \\
\text { иммуновоспалительных реакций (stealthy- } \\
\text { стратегия) }\end{array}$ \\
\hline
\end{tabular}


вляя сигнальные пути, опосредованные TLR2/4. Для бруцелл также характерна продукция модифицированного флагеллина, который является слабым индуктором TLR5. Это обеспечивает скрытую, незаметную для хозяина колонизацию клеток ММС и ингибирование интенсивности иммуновоспалительных реакций [15].

Молекулы домена TIR проявляют гомологию c TLR, cпособствуя снижению активности созревания дендритных клеток и синтезу противовоспалительного цитокина интерлейкина-10 (ИЛ-10), что в совокупности с низкой активностью LPS также способствует угнетению интенсивности воспалительных реакций $[17,18]$.

Бруцеллы проникают в фагоциты через липидный бислой, избегая его бактерицидного действия и фагосомолизосомального слияния. Эта способность бруцелл обеспечивается системой секреции IV типа (T4SS), которая включает 12 структурных генов virB1-virB12, кодирующих белковые компоненты T4SS и формирующих функциональный оперон, консервативно присутствующий у всех видов бруцелл [19-22].

Помимо T4SS, в реализации механизмов вирулентности бруцелл внутри клеток хозяина принимают участие несколько основных факторов: циклический $\beta$-1,2-глюкан, LPS и белок LuxR (регулятор VjbR, контролирует экспрессию факторов вирулентности на ранних стадиях внутриклеточной инфекции) [15].

Имеются различия во взаимодействии S- и R-форм бруцелл с клетками MMC. Бруцеллы в S-форме кооперируют с фагоцитами посредством так называемых липидных рафт (RAFT) - особых участков плазматической мембраны (микродоменов), обогащенных гликосфинголипидами и холестерином.

В инкубационный период у S-бруцелл активно экспрессируются гены, кодирующие синтез 0-фрагмента цепи LPS ( $w b o A, \operatorname{man} B)$, обеспечивающие создание условий для внутриклеточной репликации. LPS R-форм бруцелл лишен 0-специфических боковых цепей, патоген прикрепляется к плазматической мембране фагоцита с помощью белка наружной мембраны 0MP25, детектируется TLR-рецепторами и поглощается фагоцитами. Считается, что R-формы бруцелл имеют более выраженные адгезивные и инвазивные свойства $[23,24]$.

Внутри фагоцитов бруцеллы локализуются в специальной вакуоли (бруцеллосодержащая вакуоль, ВCV). Микросреда внутри BCV имеет ограниченное количество питательных веществ и закисленную агрессивную для бруцелл среду. У патогена существенно замедляется метаболизм, снижаются экспрессия генов и синтез регуляторных белков. На фоне закисления BCV активируется T4SS, запускается селективная транслокация белков и ДНК-белковых комплексов, способствующих достижению S-формами бруцелл репликативных фагосом. Y R-бруцелл внутри фагоцита T4SS обеспечивает реализацию механизмов цитотоксичности [25-27].

У бруцелл описаны ряд эффекторных белков T4SS - VceA, VceB, VceC, BspA, BspB, BspF и др., функции которых - участие В молекулярных механизмах взаимодействия со структурами эндоплазматического ретикулума и ингибирование сигнальных путей, синтеза белковых субстанций системы врожденного иммунитета хозяина [22-28].
Внутри вакуоли у бруцелл активируется двухкомпонентная регуляторно-сенсорная система адаптации - BvrR/BvrS, кодируемая опероном bvrRS Brucella (см. рисунок).

Система обеспечивает контроль экспрессии генов, ответственных за сохранение целостности клеточной оболочки, адаптивные изменения интенсивности метаболических процессов и репликации бактерий. BvrR/BvrS система контролирует экспрессию белков наружной мембраны $0 \mathrm{mp} 3 а$ (0mp25) и 0mp 3b (0mp22) [16, 18, 29].

Штаммы B. abortus с измененными свойствами клеточной мембраны (bvrRS-мутанты) менее устойчивы к кислой среде фагосом и неспособны локализоваться в эндоплазматической сети фагоцитов (место наиболее активной репликации бруцелл). Мутация в генах BvrR/BvrS препятствует проникновению $B$. abotrus в нефагоцитирующие клетки и ингибирует внутриклеточное взаимодействие. Дисфункция данной системы изменяет проницаемость внешней мембраны, экспрессию белков наружной мембраны 3-й группы (0mp 3a; Omp 3b) и структуру липида A $[18,29,30]$.

у бруцелл описаны растворимые периплазматические белки ЕipA, ЕipВ наружной мембраны, которые способствуют не только сохранению целостности клеточной оболочки, но и делению бруцелл внутри фагоцитов [31, 32].

К одному из проявлений несостоятельности врожденных механизмов иммунной защиты макроорганизма в отношении бруцелл относят формирование незавершенного фагоцитоза, связанного с нарушениями слияния бактериосодержащей вакуоли с лизосомами. Данный механизм опосредован в том числе действием циклического $\beta$-1,2-глюкана, который является частью внешней мембраны $[29,33]$.

Наиболее эффективные механизмы цитотоксичности в отношении бруцелл связаны с активностью Т-клеток CD4 ${ }^{+}$ продуцентами интерферона- $\gamma(И Ф Н-\gamma)$ и фагоцитами (преимущественно дендритными клетками), синтезирующими индуцибельную синтазу оксида азота (iNOS/NOS2). Hесостоятельность врожденных иммунных механизмов в борьбе с бруцеллами приводит к дефектным Th1-иммунным реакциям и Т-клеточной анергии - одной из основных причин хронизации инфекции [35].

Показано, что острый бруцеллез сопровождается увеличением в крови количества $\mathrm{CD}^{+}$- и $\mathrm{CD}^{+}$-лимфоцитов и существенным снижением фагоцитарной активности нейтрофилов. При хронической форме наблюдается снижение уровня Т-хелперов и Т-цитотоксических лимфоцитов. Выявленные изменения свидетельствуют о формировании вторичной иммуносупрессии как при острой (ослабление фагоцитоза), так и при хронической (снижение количества субпопуляций Т-лимфоцитов) форме течения болезни [36].

Имеются данные о формировании у больных хроническим бруцеллезом дисбаланса Th1/Th2 иммунных реакций в сторону увеличения цитокин-продуцирующей активности Th2-клеток, обеспечивающих в большей степени гуморально-опосредованный иммунитет. Повышение количества и активности Th2-клеток способствует ингибированию клеточно-опосредованного иммунитета (Th1), что также может обеспечивать хронизацию бруцеллеза [37].

У больных бруцеллезом отмечается повышение в периферической крови количества CD4+ T-регуляторных клеток (Treg). 


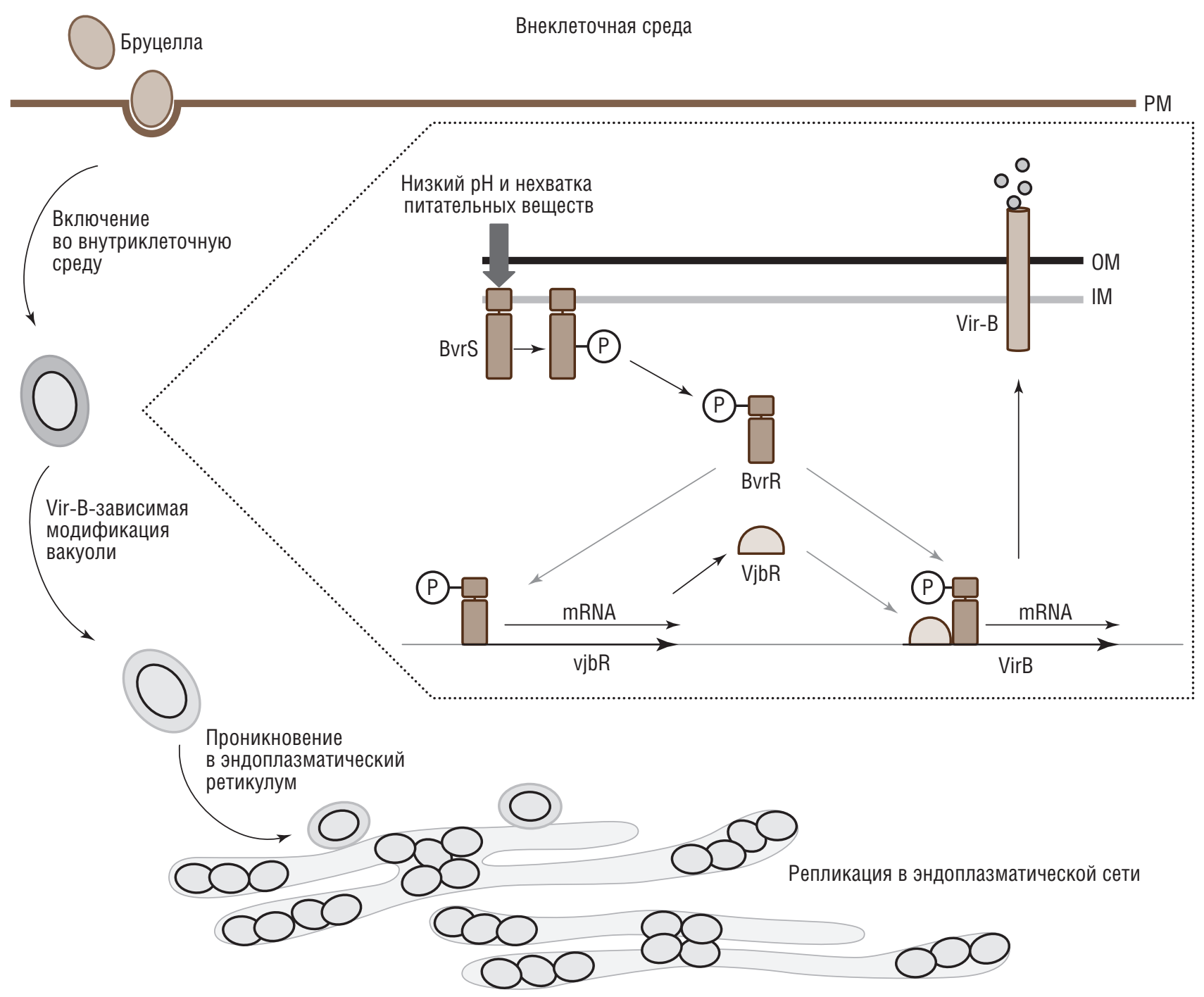

Внутриклеточная среда

Модель (схема) Авухкомпонентной регуляторно-сенсорной системы адаптации (BvrR/BvrS) у бруцемл (цит. по [34]) mRNA - матричная PHK; BvrR/BvrS - двухкомпонентная регуляторно-сенсорная система адаптации; VirB - структурные гены; vjbR - транскрипция оперона; PM - плазматическая мембрана; IM - внутренняя мембрана; ОМ - наружная мембрана.

При этом у больных хронической формой инфекции изменения более выражены. Treg подавляют пролиферацию и реактивность других субпопуляций Т-лимфоцитов, что способствует ограничению активации $\mathrm{CD}^{+}-$и $\mathrm{CD} 8^{+}$-лимфоцитов [38-40].

На начальных этапах развития иммуновоспалительной реакции при бруцеллезе у заболевших резко увеличивается количество циркулирующих Т-лимфоцитов определенного типа - V $\gamma 9 \mathrm{~V} \delta 2$ (Т- $\gamma 9 \delta 2)$, способных ингибировать внутриклеточную репликацию и выполнять специфическую роль в контроле инвазии патогена за счет реализации механизмов цитотоксичности (синтез перфоринов, гранзимов и гранулизинов, индуцированный апоптоз). При экспериментальном моделировании (in vitro) инфицирования макрофагов штаммами B. suis было показано, что патоген способствовал снижению активности Т $\gamma 9 \delta 2$, которое, вероятно, связано с ослаблением распознавания инфицированных макрофагов Т-лимфоцитами и их устойчивостью к цитотоксическому действию [41-43].
Кооперация TLR с компонентами микробной клетки бруцелл, липидом А и особой формой CpG-ДНК инициирует продукцию противовоспалительного цитокина - ИЛ-10, который способствует подавлению синтеза провоспалительных цитокинов (ИЛ-6, ИЛ-1), интерферонов, фактора некроза опухоли и снижению активности макрофагов. Важной особенностью ИЛ-10 в иммуногенезе бруцеллеза является его способность стимулировать синтез IgE, участвовать в формировании реагин-опосредованной специфической сенсибилизации организма в начальный период заболевания [44].

Определена роль ЕК-клеток (естественных киллеров, NK) в формировании специфического иммунного ответа. Показано, что интенсивность антителогенеза при введении инактивированных клеток $B$. abortus в большей степени зависела от уровня и активности ЕК-клеток и лишь частично - от концентрации ИФН- $\gamma$ или ИЛ-12. При селективном удалении ЕК установлено не менее чем двукратное снижение интенсивности выработки антител. Оценка интенсивности экспрессии 
маркеров антиген-стимулированной активации (CD69) на B- и NK-клетках показала, что антиген приводит к активации большого количества спленоцитов (моноцит, образующийся в ретикулярной ткани селезенки), однако наиболее раннюю индукцию детектировали на ЕК-клетках $[45,46]$.

Важную роль в функционировании противоинфекционного клеточно-опосредованного иммунитета играют инвариантные NKT-клетки (iNKT, фенотип $\mathrm{CD}^{+}{ }^{+} \mathrm{CD} 16^{+} \mathrm{CD} 56^{+}$) подгруппа Т-лимфоцитов (подварианты с экспрессией корецептора $\mathrm{CD}^{+}$и $\mathrm{CD}^{+}$). Доказана способность CD4 $4^{+} \mathrm{NNKT-клеток}$ ингибировать внутримакрофагальный рост бруцелл. Реализация механизмов цитотоксичности в отношении инфицированных макрофагов опосредована сочетанием растворимых, контактно-зависимых механизмов (синтез ИФН- $\gamma$ ) и цитотоксической активностью (индукция пути Fas, высвобождение литических гранул) [47].

У больных острым бруцеллезом наблюдается увеличение количества NKT-клеток в периферической крови, что, вероятно, обусловлено недостаточностью иммунного ответа со стороны NK-клеток и снижением числа Т-лимфоцитов в случае невозможности элиминации бруцелл иммунокомпетентными клетками [48].

Известно, что у больных бруцеллезом формируются реакции гиперчувствительности немедленного - IgE-зависимого и замедленного - лимфоцит-опосредованного типов. У больных острым бруцеллезом с высокой степенью IgE-зависимой специфической сенсибилизации установлено формирование выраженной иммуносупрессии. Повышение уровня лимфоцит-опосредованной специфической сенсибилизации обратно коррелирует с выраженностью патофизиологических изменений в иммунном статусе $[49,50]$.

\section{Анализ иммунопатологической коншепции}

Анализ научных публикаций по проблеме патогенеза бруцеллезной инфекции позволяет выделить 4 основных этапа в процессе, посредством которого внутриклеточная бактерия вызывает длительную инфекцию (хронизацию): инвазия в организм хозяина, характеризующаяся периодами локализации и адаптации к условиям среды обитания; создание ниши для выживания и размножения внутри клеток-мишеней (эпителиальные или способные к фагоцитозу клетки); противостояние механизмам естественной резистентности и преодоление адаптивного иммунитета.

Большинство факторов вирулентности бруцелл обеспечивает реализацию первых двух этапов (вторжение в клетки-мишени, адаптация и интрацеллюлярное размножение). Важным механизмом патогенного действия бруцелл, обеспечивающим длительную внутриклеточную локализацию возбудителя, является ингибирование апоптоза, что способствует сохранению «комфортной» среды для размножения бруцелл и их защиты от элиминации. Вместе с тем бруцеллы способны индуцировать апоптоз Т-лимфоцитов, что обеспечивает защиту от адаптивного иммунитета.

Продолжительный инкубационный период бруцеллезной инфекции, вероятно, обусловлен ингибированием бруцеллами врожденного иммунитета, что отражается в первую очередь на ММС. После проникновения в организм хозяина бруцеллы защищают себя от факторов естественной резистентности - распознавание TLR и агрессивное действие системы комплемента. Ослабление способности иммунокомпетентных клеток хозяина обнаруживать антигенные детерминанты бруцелл оказывает эффект снижения интенсивности воспалительной реакции организма и в конечном счете провоцирует ослабление цитотоксической активности CD8 ${ }^{+}$лимфоцитов, снижает потенциал естественного (слабая презентация фагоцитами и дендритными клетками экзогенных белков) и адаптивного иммунитета против бруцелл, что и приводит к хронизации инфекции.

Макрофаги и дендритные клетки считаются ключевыми элементами врожденного иммунного ответа против внутриклеточных бактерий, таких как бруцелла. На начальных стадиях после инфицирования организма хозяина бруцелль незаметно колонизируют клетки-мишени без манифестации иммуновоспалительной реакции. Типичный антибактериальный иммунный ответ - приток микрофагов к очагу инфекции - не формируется. T4SS бруцелл инициирует активацию интерферон-регулируемых генов, генерируемый иммунный ответ недостаточен, чтобы элиминировать патоген.

В случае адаптации бруцелл к среде внутри макрофагов патоген расширяет локализацию, мигрируя в ткани опорнодвигательной, мочеполовой, сердечно-сосудистой (эндотелий) и нервной систем.

Важнейшее патогенетическое значение имеет формирование специфической гиперчувствительности. Учитывая внутриклеточный паразитизм, бруцеллы длительно персистируют в организме хозяина, вызывая его специфическую сенсибилизацию за счет образования эндотоксина, продуктов жизнедеятельности, антигенемии, что проявляется в инициации патофизиологической стадии развития аллергической реакции. Повышение степени IgE-зависимой специфической сенсибилизации ассоциировано с формированием выраженной иммуносупрессии. Первичная генерализация бруцеллезной инфекции обычно протекает на фоне отрицательных кожно-аллергических проб, соответственно отсутствие или низкая специфическая сенсибилизация лимфоцитов на фоне подавленного фагоцитоза обусловливает несостоятельность клеточного иммунитета. В свою очередь, нозогенная иммуносупрессия, инициированная возбудителем, является причиной массивной бактериемии с формированием вторичных очагов инфекции - «микробное депо» (лимфатические узлы, селезенка, костный мозг).

Реакция гиперчувствительности замедленного типа, обусловленная клеточными факторами иммунитета, преимущественно лимфоцитами, по своей сути - специфический иммунный механизм защиты, который направлен на локализацию и дальнейшую элиминацию возбудителя через специфическое гранулематозное воспаление. Соответственно интенсивность специфической реактивности лимфоцитов является отражением интенсивности (силы) противобруцеллезного клеточного иммунитета.

Исходя из вышеизложенного можно заключить, что высокий уровень специфической клеточно-опосредованной сенсибилизации не ассоциирован с формированием 
иммуносупрессии при бруцеллезе. Вероятно, это обусловлено тем, что активность клеточных механизмов иммунитета, в частности лимфоцитов, является определяющей при бактериальных инфекциях с внутриклеточным паразитированием, соответственно высокая интенсивность лимфоцит-зависимой сенсибилизации в большей степени отражает устойчивость к патогену.

Можно предположить, что наиболее опасным при остром бруцеллезе с точки зрения генерализации этиологического агента (возбудителя бруцеллеза) с переходом в хронический бруцеллез, а также большого риска активизации условнопатогенной микрофлоры или вторичного наслоения патогенных микроорганизмов является течение болезни с высокой степенью реагин-зависимой и низкой интенсивностью клеточно-опосредованной специфической сенсибилизации. Соответственно больным бруцеллезом с выраженной IgEобусловленой аллергизацией необходима более длительная антибактериальная терапия с включением в схему лечения десенсибилизирующих средств и иммуномодуляторов, а больным с низкой интенсивностью лимфоцит-зависимой сенсибилизации - назначение стимуляторов клеточного иммунитета.

Таким образом, проявление патогенных свойств бруцелл и их «судьба» в организме хозяина тесно ассоциированы с воздействием на патоген факторов врожденного иммунитета. На исход «борьбы» естественного иммунитета с бруцеллами оказывает влияние баланс между продуктивными и контрпродуктивными эффектами противодействующих сил. При физиологически нормальном функционировании иммунной системы вектор иммунологических реакций при бруцеллезе будет определяться свойствами патогена: способностью к блокировке завершенного фагоцитоза (преимущественно результат действия T4SS), ингибированию апоптоза инфицированных фагоцитов, индукции анергии при формировании иммуновоспалительной реакции (ингибирование созревания антиген-презентирующих клеток, премирования Т-лимфоцитов).

Патогенетической основой практически закономерной трансформации острой стадии инфекции в хроническую является индуцированная патогеном несостоятельность иммунитета в отношении бруцелл с созданием условий для незавершенного фагоцитоза и долгосрочного внутриклеточного паразитирования. Исход при бруцеллезе определяется прежде всего состоянием именно клеточного иммунитета, так как инфекция часто протекает на фоне достаточно высокого уровня циркулирующих антител, которые не обеспечивают защиту макроорганизма и не препятствуют формированию бактерионосительства.

Состояние проблемы бруцеллезной инфекции требует продолжения изучения особенностей специфической сенсибилизации как одного из ведущих механизмов в патогенезе бруцеллеза, а также совершенствования диагностики, прогнозирования течения болезни и терапии.

Исследование патофизиологических особенностей бруцеллеза с выявлением существующих взаимосвязей многочисленных клинических проявлений с лежащими в их основе индивидуальными физиологическими и патологическими реакциями организма на данную инфекцию позволят объективизировать критерии активности инфекционного процесса. Накопленные данные о биологии бруцелл определяют дальнейшее развитие научных исследований, направленных на разработку активных соединений и изучение их действия на компоненты главного фактора патогенности бруцелл систему секреции IV типа, реализация потенциала которой обеспечивает возбудителю бруцеллеза выживаемость, адаптацию и персистенцию в организме хозяина.

Результаты исследований последних лет позволяют сформировать иммунопатологическую концепцию для понимания развития болезни, основанной на закономерностях молекулярно-клеточных механизмов взаимодействия бруцелл с факторами естественного и адаптивного иммунитета хозяина.

Очевидно, что особенности инвазии и дальнейшей персистенции бруцелл, а также инфекционно-аллергический характер бруцеллеза указывают на определяющую роль нарушений иммунитета в патогенезе заболевания. Наиболее яркой спецификой иммунопатогенеза бруцеллеза является многообразие способов защиты возбудителя от иммунной системы макроорганизма, что лежит в основе персистенции возбудителя и возможности развития хронических форм заболевания.

\section{СВЕАЕНИЯ ОБ АВТОРАХ}

Пономаренко Дмитрий Григорьевич (Dmitry G. Ponomarenko) - кандидат биологических наук, заведующий лабораторией бруцеллеза ФКУЗ Ставропольский противочумный институт Роспотребнадзора, Ставрополь, Российская Федерация E-mail: ponomarenko.dg@gmail.com https://orcid.org/0000-0003-0422-6755

Саркисян Нушик Сааковна (Nushik S. Sarkisyan) - кандидат медицинских наук, заведующая отделом консультационно-профилактической работы, врач клинической лабораторной диагностики ФКУЗ Ставропольский противочумный институт Роспотребнадзора, Ставрополь, Российская Федерация

E-mail:nyshik25@yandex.ru

https://orcid.org/0000-0003-3512-5738

Куличенко Александр Николаевич (Alexandr N. Kulichenko) - член-корреспондент РАН, доктор медицинских наук, профессор, директор ФКУЗ Ставропольский противочумный институт Роспотребнадзора, Ставрополь, Российская Федерация

E-mail: kulichenko_an@list.ru

https://orcid.org/0000-0002-9362-3949 


\section{ヘИТЕРАТУРA}

1. Брико Н.И., Онищенко Г.Г., Покровский В.И. Руководство по эпиАемиологии инфекционных болезней : в 2 т. Т. 1. Москва : Медицинское информационное агентство, 2019. 880 с.

2. Amjadi O., Rafiei A., Mardani M., Zafari P., Zarifian A. A review of the immunopathogenesis of Brucellosis // Infect. Dis. (Lond.). 2019. Vol. 51, N 5. P. 321-333. DOl: https://doi.org/10.1080/23744235.2019.1568545

3. Moreno E. et al. Brucella melitensis: a nasty bug with hidden credentials for virulence // Proc. Natl Acad. Sci. USA. 2002. Vol. 99. P. 1-3.

4. Moreno-Lafont M.C. et al. Antigen-specific activation and proliferation of CD4+ and CD8+ T lymphocytes from brucellosis patients // Trans. R. Soc. Trop. Med. Hyg. 2002. Vol. 96, N 3. P. 340-347.

5. Barquero-Calvo E. et al. Brucella abortus induces the premature death of human neutrophils through the action of its lipopolysaccharide // PLoS One. 2015. Vol. 11, N 5. Article ID e1004853.

6. Byndloss M.X. et al. Brucella spp. virulence factors and immunity // Annu. Rev. Anim. Biosci. 2016. Vol. 4. P. 111-127.

7. Hartigh A.B. et al. VirB3 to VirB6 and VirB8 to VirB11, but not VirB7, are essential for mediating persistence of Brucella in the reticuloendothelial system // J. Bacteriol. 2008. Vol. 190. P. 4427-4436.]

8. Roset M.S., Ibañez A.E., de Souza Filho J.A. et al. Brucella cyclic $\beta$-1,2-glucan plays a critical role in the induction of splenomegaly in mice // PLoS One. 2014. Vol. 9, N 7. Article ID e101279. DOI: https:// doi.org/10.1371/journal.pone.0101279

9. Kaplan-Türköz B., Koelblen T., Felix C. et al. Structure of the Toll/ interleukin 1 receptor (TIR) domain of the immunosuppressive Brucella effector BtpA/Btp1/TcpB // FEBS Lett. 2013. Vol. 587. P. 3412-3416. DOI: https://doi.org/10.1016/j.febslet.2013.09.007

10. Аубровина В.И., Коновалова Ж.А., Ястремская К.Ю., Баранникова Н.^., Токарева А.Е., Балахонов С.В. Механизмы клеточного иммунного ответа при бруцемлезе // Эпидемиология и вакцинопрофилактика. 2016. Т. 15, № 6. С. 80-87.

11. Покровский В.И., Пак С.Г., Брико Н.И., Ааниякин Б.К. Инфекци онные болезни и эпиАемиология : учебник. 2-е изА. Москва : ГЭОТАРМедиа, 2007. 816 с.

12. de Figueiredo P., Ficht T.A., Rice-Ficht A. et al. Pathogenesis and immunobiology of brucellosis: review of Brucella-host interactions // Am J. Pathol. 2015. Vol. 185, N 6. P. 1505-1517. DOI: https://doi.org/10.1016/ j.ajpath.2015.03.003

13. Малов В.А. Терапевтические маски бруцемлеза // Фарматека. 2011. № 4. C. 22-28.

14. Sauret J.M., Vilissova N. Human brucellosis // J. Am. Board Fam. Pract. 2002. Vol. 15, N 5. P. 401-406.

15. Kleinman C.L. et al. ChIP-seq analysis of the LuxR-type regulator VjbR reveals novel insights into the Brucella virulence gene expression network // Nucleic Acids Res. 2017. Vol. 45, N 10. P. 5757-5769.

16. Guzman-Verri C. et al. The two-component system BvrR/BvrS essential for Brucella abortus virulence regulates the expression of membrane proteins with counterparts in members of the Rhizobiaceae // Proc. Natl Acad. Sci. USA. 2008. Vol. 99. P. 12 375-12 380.

17. Döhmer P.H. et al. Identification of a type IV secretion substrate of Brucella abortus that participates in the early stages of intracellular survival // Cell. Microbiol. 2014. Vol. 16, N 3. P. 396-410.

18. Byndloss M.X. et al. How bacterial pathogens use type III and type IV secretion systems to facilitate their transmission // Curr. Opin. Microbiol. 2017. Vol. 35. P. 1-7.

19. Ke Y., Wang Y., Li W., Chen Z. Type IV secretion system of Brucella spp. and its effectors // Front. Cell. Infect. Microbiol. 2015. Vol. 5. P. 72.

20. Mary C., Fouillen A., Bessette B. et al. Interaction via the $\mathrm{N}$ terminus of the type IV secretion system (T4SS) protein VirB6 with VirB10 is required for VirB2 and VirB5 incorporation into T-pili and for T4SS function // J. Biol. Chem. 2018. Vol. 293, N 35. P. 13 415-13 426.

21. Кулаков Ю.К. Молекулярные аспекты персистенции бруцемл // Молекулярная генетика, микробиология и вирусология. 2016. № 1. С. 3-8.

22. ГорчаковаН.Г.Особенностипаразитарнойсистемыбруцемлеза// Научно-исследовательские публикации. 2017. № 4. С. 14-27.

23. Olsen S.C. et al. Advancement of knowledge of Brucella over the past 50 years // Vet. Pathol. 2014. Vol. 51, N 6. P. 1076-1089.

24. Barquero-Calvo E. et al. Brucella abortus induces the premature death of human neutrophils through the action of its lipopolysaccharide // PLoS One. 2015. Vol. 11, N 5. Article ID e1004853.
25. Celli J. et al. Brucella evades macrophage killing via VirB-dependent sustained interactions with the endoplasmic reticulum // J. Exp. Med. 2003. Vol. 198. P. 545-556.

26. Myeni S., Child R., Ng T.W. et al. Brucella modulates secretory trafficking via multiple type IV secretion effector proteins // J. PLoS Pathog. 2013. Vol. 9. Article ID e100356.

27. Xavier M.N. et al. Pathogenesis of Brucella spp. // Open Vet. Sci. J. 2010. Vol. 4. P. 109-118.

28. Roop R.M. et al. Survival of the fittest: how Brucella strains adapt to their intracellular niche in the host // Med. Microbiol. Immunol. 2009 Vol. 198, N 4. P. 221-238.

29. Herrou J. et al. Periplasmic protein EipA determines envelope stress resistance and virulence in Brucella abortus // Mol. Microbiol. 2019. Vol. 111, N 3. P. 637-661.

30. Herrou J., Willett J.W., Fiebig A. et al. Brucella periplasmic protein EipB is a molecular determinant of cell envelope integrity and virulence // J. Bacteriol. 2019. Vol. 201, N 12. Article ID e0013419. DOI: https:// doi.org/10.1128/JB.00134-19

31. Poester F.P., Samartino L.E., Santos R.L. Pathogenesis and pathobiology of brucellosis in livestock // Rev. Sci. Tech. 2013. Vol. 32, N 1. P. $105-115$

32. Altamirano-Silva P., Meza-Torres J., Castillo-Zeledón A. et al. Brucella abortus senses the intracellular environment through the BvrR/BvrS two-component system, which allows B. abortus to adapt to its replicative niche // Infect. Immun. 2018. Vol. 86, N 4. P. 713-717.

33. Forestier $\mathrm{C}$. et al. Brucella abortus lipopolysaccharide in murine peritoneal macrophages acts as a down-regulator of T cell activation // Immunology. 2000. Vol. 165, N 9. P. 5202-5210.

34. ^огвиненко О.В., Ракитина Е.^., Пономаренко А.Г., Костюченко М.В., Саркисян Н.С., Бердникова Т.В. Особенности иммунологических показателей крови у больных различными формами бруцемлеза // Инфекция и иммунитет. 2013. Т. 3, № 3. С. 275-278.

35. Zheng R. et al. Meta-analysis of the changes of peripheral blood T cell subsets in patients with brucellosis // J. Immunol. Res. 2018 Vol. 2018. Article ID 8439813

36. Железникова Г.Ф. Регуляторные Т-лимфоциты в иммунном ответе на инфекцию // Журнал инфектологии. 2011. № 1. С. 6-13.

37. Bahador $A$. et al. Frequencies of $C D 4+T$ regulatory cells and their CD25high and FoxP3high subsets augment in peripheral blood of patients with acute and chronic brucellosis // Osong Public Health Res. Perspect. 2014. Vol. 5, N 3. P. 161-168.

38. Shevach E. et al. Control of T cell activation by CD4+CD25+ sup pressor T cells // Immunol. Rev. 2001. Vol. 182. P. 58-67.

39. De P. et al. Structural determinants in a glucose-containing lipopolysaccharide from Mycobacterium tuberculosis critical for inducing a subset of protective T cells // J. Biol. Chem. 2018. Vol. 293, N 25 P. 9706-9717.

40. Kilic S.S. et al. Gamma/delta T cells in patients with acute brucelIosis // Clin. Exp. Med. 2009. Vol. 9, N 2. P. 101-104.

41. Liautard J. et al. Identification and isolation of Brucella suis virulence genes involved in resistance to the human innate immune system // Infect. Immun. 2007. Vol. 75, N 11. P. 5167-5174.

42. De Long M.F., Tsolis R.M. Brucellosis and type IV secretion // Future Microbiol. 2012. Vol. 7, N 1. P. 47-58.

43. Dornand J. et al. Impairment of intramacrophagic Brucella suis multiplication by human natural killer cells through a contact-dependent mechanism // Infect. Immun. 2004. Vol. 72, N 4. P. 2303-2311.

44. Gao Ning et al. Regulatory role of natural killer (NK) cells on antibody responses to Brucella abortus // Innate Immun. 2011. Vol. 17, N 2. P. 152-163.

45. Bessoles S. et al. Human CD4+ invariant NKT cells are involved in antibacterial immunity against Brucella suis through CD1d-dependent but CD4-independent mechanisms // Eur. J. Immunol. 2009. Vol. 39, N 4. P. $1025-1035$.

46. Ракитина Е.^., Аогвиненко О.В., Пономаренко А.Г., Костюченко М.В., Борздова И.Ю., Голубь О.Г. Анализ содержания NКТ-лимфоцитов у больных острым и хроническим бруцемлезом // Актуальные проблемы болезней, общих Аля человека и животных : материалы І Всероссийской научно-практической конференции. 2017. С. $273-$ 275. 
47. Пономаренко А.Г., Логвиненко О.В., Саркисян Н.С., Ракитина Е.А., Голубь О.Г., Куличенко А.Н. Новый подхоА к аммергодиагностике бруцемлеза // Инфекция и иммунитет. 2013. Т. 3, № 1. С. 89 92
48. Саркисян Н.С., ПономаренкоА.Г., Аогвиненко О.В., Ракитина Е.^., Костюченко М.В., Куличенко А.Н. Интенсивность специфической сенсибилизации и иммунный статус у больных бруцемезом // Медицинская иммунология. 2016. Т. 18, № 4. С. 365-372.

\section{REFERENCES}

1. Briko N.I., Onishchenko G.G., Pokrovsky V.I. Guidelines for the epidemiology of infectious diseases. In 2 vols. Vol. 1. Moscow: Meditsinskoe informatsionnoe agentstvo, 2019: 880 p. (in Russian)

2. Amjadi O., Rafiei A., Mardani M., Zafari P., Zarifian A. A review of the immunopathogenesis of Brucellosis. Infect Dis (Lond). 2019; 51 (5): 321-33. DOI: https://doi.org/10.1080/23744235.2019.1568545

3. Moreno E., et al. Brucella melitensis: a nasty bug with hidden cre dentials for virulence. Proc Natl Acad Sci USA. 2002; 99: 1-3.

4. Moreno-Lafont M.C., et al. Antigen-specific activation and proliferation of CD4+ and CD8+ T lymphocytes from brucellosis patients. Trans R. Soc. Trop. Med. Hyg. 2002; 96 (3): 340-7.

5. Barquero-Calvo E., et al. Brucella abortus induces the premature death of human neutrophils through the action of its lipopolysaccharide. PLoS One. 2015; 11 (5): e1004853.

6. Byndloss M.X., et al. Brucella spp. virulence factors and immunity. Annu Rev Anim Biosci. 2016; 4: 111-27.

7. Hartigh A.B., et al. VirB3 to VirB6 and VirB8 to VirB11, but not VirB7, are essential for mediating persistence of Brucella in the reticuloendothelial system. J Bacteriol. 2008; 190: 4427-36.]

8. Roset M.S., Ibañez A.E., de Souza Filho J.A., et al. Brucella cyclic $\beta$-1,2-glucan plays a critical role in the induction of splenomegaly in mice. PLoS One. 2014; 9 (7): e101279. DOI: https://doi.org/10.1371/journal. pone.0101279

9. Kaplan-Türköz B., Koelblen T., Felix C., et al. Structure of the Toll/ interleukin 1 receptor (TIR) domain of the immunosuppressive Brucella effector BtpA/Btp1/TcpB. FEBS Lett. 2013; 587: 3412-6. DOI: https:// doi.org/10.1016/j.febslet.2013.09.007

10. Dubrovina V.I., Konovalova Z.A., Yastremskaya K.U., Barannikova N.L., Tokareva L.E., Balakhonov S.V. The mechanisms of cellular immune response in brucellosis. Epidemiologiya i vaktsinoprofilaktika [Epidemiology and Vaccine Prophylaxis]. 2016; 15 (6): 80-7. URL: https:// doi.org/10.31631/2073-3046-2016-15-6-80-87 (in Russian)

11. Pokrovskiy V.I., Pak S.G., Briko N.I., Danilkin B.K. Infectious diseases and epidemiology: Textbook. 2nd ed. Moscow: GEOTAR-Media, 2007: 816 p. (in Russian)

12. de Figueiredo P., Ficht T.A., Rice-Ficht A., et al. Pathogenesis and immunobiology of brucellosis: review of Brucella-host interactions Am J Pathol. 2015; 185 (6): 1505-17. DOI: https://doi.org/10.1016/ j.ajpath.2015.03.003

13. Malov V.A. Therapeutic masks for brucellosis. Farmateka [Pharmateca]. 2011; (4): 22-8. (in Russian)

14. Sauret J.M., Vilissova N. Human brucellosis. J Am Board Fam Pract. 2002; 15 (5): 401-6.

15. Kleinman C.L., et al. ChIP-seq analysis of the LuxR-type regulator VjbR reveals novel insights into the Brucella virulence gene expression network. Nucleic Acids Res. 2017; 45 (10): 5757-69.

16. Guzman-Verri C., et al. The two-component system BvrR/BvrS essential for Brucella abortus virulence regulates the expression of membrane proteins with counterparts in members of the Rhizobiaceae. Proc Natl Acad Sci USA. 2008; 99: 12 375-80.

17. Döhmer P.H., et al. Identification of a type IV secretion substrate of Brucella abortus that participates in the early stages of intracellular survival. Cell Microbiol. 2014; 16 (3): 396-410.

18. Byndloss M.X., et al. How bacterial pathogens use type III and type IV secretion systems to facilitate their transmission. Curr Opin Microbiol. 2017; 35: 1-7.

19. Ke Y., Wang Y., Li W., Chen Z. Type IV secretion system of Brucella spp. and its effectors. Front Cell Infect Microbiol. 2015; 5: 72

20. Mary C., Fouillen A., Bessette B., et al. Interaction via the $\mathrm{N}$ terminus of the type IV secretion system (T4SS) protein VirB6 with VirB10 is required for VirB2 and VirB5 incorporation into T-pili and for T4SS function. J Biol Chem. 2018; 293 (35) 13 415-426.

21. Kulakov Yu.K. Molecular aspects of Brucella persistence. Molekulyarnaya genetika, mikrobiologiya i virusologiya [Molecular Genetics, Microbiology, Virology]. 2016; (1): 3-8. (in Russian)
22. Gorchakova N.G. Features of the parasitic system of brucellosis Nauchno-issledovatel'skie publikatsii [Research Publications]. 2017; (4): 14-27. (in Russian)

23. Olsen S.C., et al. Advancement of knowledge of Brucella over the past 50 years. Vet Pathol. 2014; 51 (6): 1076-89.

24. Barquero-Calvo E., et al. Brucella abortus induces the premature death of human neutrophils through the action of its lipopolysaccharide. PLoS One. 2015; 11 (5) e1004853.

25. Celli J., et al. Brucella evades macrophage killing via VirB-dependent sustained interactions with the endoplasmic reticulum. J Exp Med. 2003; 198: 545-56.

26. Myeni S., Child R., Ng T.W., et al. Brucella modulates secretory traf ficking via multiple type IV secretion effector proteins. J PLoS Pathog. 2013; 9: e100356.

27. Xavier M.N., et al. Pathogenesis of Brucella spp. Open Vet Sci J. 2010; 4: 109-18.

28. Roop R.M., et al. Survival of the fittest: how Brucella strains adapt to their intracellular niche in the host. Med Microbiol Immunol. 2009; 198 (4): 221-38.

29. Herrou J., et al. Periplasmic protein EipA determines envelope stress resistance and virulence in Brucella abortus. Mol Microbiol. 2019; 111 (3): 637-61.

30. Herrou J., Willett J.W., Fiebig A., et al. Brucella periplasmic protein EipB is a molecular determinant of cell envelope integrity and virulence. J Bacteriol. 2019; 201 (12): e0013419. DOI: https://doi.org/10.1128/ JB.00134-19

31. Poester F.P., Samartino L.E., Santos R.L. Pathogenesis and pathobiology of brucellosis in livestock. Rev Sci Tech. 2013; 32 (1): 105-15.

32. Altamirano-Silva P., Meza-Torres J., Castillo-Zeledón A., et al. Brucella abortus senses the intracellular environment through the BvrR/BvrS two-component system, which allows $B$. abortus to adapt to its replicative niche. Infect Immun. 2018; 86 (4): 713-7.

33. Forestier C., et al. Brucella abortus lipopolysaccharide in murine peritoneal macrophages acts as a down-regulator of T cell activation. Immunology. 2000; 165 (9): 5202-10.

34. Logvinenko O.V., Rakitina E.L., Ponomarenko D.G., Kostyuchenko M.V., Sarkisyan N.S., Berdnikiva T.V. Features of immunological parameters of blood in patients with various forms of brucellosis. Infektsiya i immunitet [Infection and Immunity]. 2013; 3 (3): 275-8. (in Russian)

35. Zheng R., et al. Meta-analysis of the changes of peripheral blood T cell subsets in patients with brucellosis. J Immunol Res. 2018; 2018: 8439813.

36. Zheleznokova G.F. Regulatory T-lymphocytes in the immune response to infection. Zhurnal infektologii [Journal of Infectology]. 2011; (1) 6-13.

37. Bahador A., et al. Frequencies of CD4 $+\mathrm{T}$ regulatory cells and their CD25high and FoxP3high subsets augment in peripheral blood of patients with acute and chronic brucellosis. Osong Public Health Res Perspect. 2014; 5 (3): 161-8.

38. Shevach E., et al. Control of T cell activation by CD4+CD25+ sup pressor T cells. Immunol Rev. 2001; 182: 58-67.

39. De P., et al. Structural determinants in a glucose-containing lipopolysaccharide from Mycobacterium tuberculosis critical for inducing a subset of protective T cells. J Biol Chem. 2018; 293 (25): 970617.

40. Kilic S.S., et al. Gamma/delta T cells in patients with acute brucellosis. Clin Exp Med. 2009; 9 (2): 101-4.

41. Liautard J., et al. Identification and isolation of Brucella suis virulence genes involved in resistance to the human innate immune system. Infect Immun. 2007; 75 (11): 5167-74.

42. De Long M.F., Tsolis R.M. Brucellosis and type IV secretion. Future Microbiol. 2012; 7 (1): 47-58.

43. Dornand J., et al. Impairment of intramacrophagic Brucella suis multiplication by human natural killer cells through a contact-dependent mechanism. Infect Immun. 2004; 72 (4): 2303-11. 
44. Gao Ning, et al. Regulatory role of natural killer (NK) cells on antibody responses to Brucella abortus. Innate Immun. 2011; 17 (2): 152-63.

45. Bessoles S., et al. Human CD4+ invariant NKT cells are involved in antibacterial immunity against Brucella suis through CD1d-dependent but CD4-independent mechanisms. Eur J Immunol. 2009; 39 (4): 102535 .

46. Rakitina E.L., Logvinenko O.V., Ponomarenko D.G., Kostyuchenko M.V., Borzdova I.Yu., Golub O.G. Analysis of the content of NKT-lymphocytes in patients with acute and chronic brucellosis. In: Actual problems of dis- eases common to humans and animals: materials of the II All-Russian Scientific-Practical Conference. 2017: 273-5. (in Russian)

47. Ponomarenko D.G., Logvinenko O.V., Sarkisian N.S., Rakitina C.L, Golub O.G., Kulichenko A.N. A new approach to Brucellosis allergodiagnostics. Infektsiya i immunitet [Infection and Immunity]. 2013: 3 (1): 89-92. (in Russian)

48. Sarkisyan N.S., Ponomarenko D.G., Logvinenko V.O., Rakitina E.L., Kostyuchenko M.V., Kulichenko A.N. Intensity of specific sensitization and immune profile in patients with Brucellosis. Meditsinskaya immunologiya [Medical Immunology (Russia)]. 2016; 18 (4): 365-72. (in Russian). DOI: https://doi.org/10.15789/1563-0625-2016-4-365-372 